\title{
Capacidade geral e específica de combinação de caracteres do fruto do maracujazeiro doce (Passiflora alata Curtis)
}

\author{
General and specific combining ability of fruit characteristics of sweet passion fruit plant (Passiflora \\ alata Curtis)
}

\author{
Maricelma Simiano JungI Eduardo Alano Vieira' ${ }^{\text {II }}$ Ademar Brancker ${ }^{\text {II }}$ \\ Rubens Onofre Nodari ${ }^{\mathrm{IV}}$
}

\section{RESUMO}

O Passiflora alata Curtis é uma planta frutífera que vem despertando interesse econômico por suas características ornamentais, medicinais, organolépticas e nutricionais. Contudo, precisam ser superados alguns entraves tecnológicos em relação ao seu cultivo, tais como a ausência de cultivares que apresentem frutos com alto rendimento de polpa, casca fina e alto grau Brix. Neste trabalho, objetivouse analisar as bases genéticas dos caracteres do fruto do maracujazeiro doce, avaliando-se sua capacidade combinatória. Para isso, foi utilizado um cruzamento dialelo parcial, envolvendo $36 F_{1}$ s e os 12 genitores. Foram estimadas a Capacidade Geral de Combinação - CGC e a Capacidade específica de Combinação - CEC para os caracteres peso do fruto, peso da polpa, espessura da casca, grau Brix e rendimento de polpa. Não foram encontradas diferenças estatisticamente significativas para CGC nos caracteres: peso do fruto, peso da polpa e grau Brix. Em relação à CEC, não se encontraram diferenças estatisticamente significativas, para todos os caracteres analisados, o que demonstra haver a predominância de variabilidade para efeitos gênicos aditivos, devendo-se, por isso, fazer seleção para caracteres com maior herdabilidade. Dos genitores, destacaram-se a mãe 2, a mãe 6 e o pai 5, por exibirem a melhor média do ranking, sendo plantas promissoras para possíveis cruzamentos dirigidos, visando à obtenção de progênies superiores para os caracteres avaliados.

Palavras-chave: melhoramento de frutíferas, frutífera nativa, dialélico, rendimento em polpa, maracujá.

\section{ABSTRACT}

The Passiflora alata Curtis is a fruit plant with increasing economical interest because its esthetic, medicinal, organoleptics and nutritional characteristics. However, some technological problems need to be overcome concerning its utilization, such as the absence of cultivar presenting fruits with high pulp revenue, fine skin and high Brix degree. This research was aimed at to analyzing the genetic basis of the fruit characteristics of the sweet passion fruit plant, by evaluating the combining ability. To achieve the goals, it was used a partial diallel, involving $36 \mathrm{~F} 1 \mathrm{~s}$ and the 12 parental. It was estimated the General Combining Ability - GCA and the Specific Combining Ability - SCA for weigh of the fruit, weight of the pulp, thickness of the skin, Brix degree and pulp revenue. There were not found statistically significant differences in GCA values weight of the fruit, weight of the pulp and Brix degree. The SCA values also did not show statistically significant differences for all the characteristics analyzed, which show that the variability is predominately due to addictive gene effects. One should, for this reason, do selection for characteristics with larger inheritance. Among the genitors evaluated, mother 2, mother 6 and father 5 were outstanding, because they exhibited the best ranking average, being promising plants for future crosses in order to obtain superior progenies for agronomic traits.

Key words: fruit breeding, native fruit, diallel, pulp revenue, passion fruit.

\section{INTRODUÇÃO}

Dentre as frutíferas que estão despertando interesse econômico no Brasil, está o maracujazeiro doce (Passiflora alata Curtis), cujo fruto evidencia um sabor único (apreciado pelos consumidores), sabor doce-acidulado, e é consumido principalmente na forma

IUniversidade do Sul de Santa Catarina (UNISUL). Av. José Acácio Moreira, n. 787, CP. 370, 88704-900, Tubarão, SC, Brasil.

"Embrapa Cerrados, BR 020, Km 18, 73310-970, Planaltina, DF, Brasil. E:mail: vieiraea@cpac.embrapa.br.

II'Empresa de Pesquisa Agropecuária e Extensão Rural de Santa Catarina. Rod. SC 446, Km 19, CP. 49, 88840-000, Urussanga, SC, Brasil.

IV Universidade Federal de Santa Catarina, Centro de Ciências Agrárias, Programa de Pós-graduação em Recursos Genéticos Vegetais, C.P. 476, 88040-900, Florianópolis, SC, Brasil. E-mail: nodari@cca.ufsc.br Autor para correspondência. 
in natura (JUNQUEIRA et al., 2005). Na composição dos frutos, são encontrados elevados teores de açúcares, vitaminas (A, B e C), sais minerais (destaque para cálcio, ferro e fósforo) e substâncias com potencial farmacológico (COSTA \& TUPINAMBÁ, 2005). Entretanto, KUSBKOSKI et al. (2006) relataram que o suco e a polpa de fruta do maracujazeiro não evidenciam elevada atividade antioxidante. Além disso, subprodutos da industrialização do maracujazeiro azedo (Passiflora edulis Sims), como as sementes, apresentam potencial para utilização na alimentação humana e animal, em função de evidenciarem elevados percentuais de óleos, proteínas e fibras (FERRARI et al., 2004).

O gênero Passiflora é, essencialmente, americano, uma vez que a maior parte das espécies tem sua origem em zonas intertropicais no continente americano (SOUZA \& MELETTI, 1997) e evidenciam como principal centro de distribuição região CentroNorte do Brasil (FALEIRO et al., 2005).

O maracujazeiro doce é uma planta alógama que expressa elevada variabilidade genética, possível de ser usada para fins de melhoramento. Entretanto, para que esta variabilidade possa ser utilizada com maior eficiência, é necessário o conhecimento das relações genéticas entre genótipos que podem ser usados em cruzamentos, em razão de que esse conhecimento serve de base para a tomada de decisões na escolha das melhores combinações genéticas. Tais combinações dão origem às populações segregantes, que são o alvo de seleção. A escolha dos genitores apenas com base em caracteres desejáveis (desempenho por si só) é insuficiente para assegurar a obtenção de progênies com elevada freqüência de segregantes transgressivos. É necessário, portanto, que os genótipos utilizados nos cruzamentos evidenciem capacidade combinatória em nível expressivo para produzirem, em alta freqüência, recombinações favoráveis (ALLARD, 1999). Conseqüentemente, qualquer progresso genético que ocorra em progênies provenientes de cruzamentos entre genitores escolhidos com base apenas no fenótipo poderá ser aleatório e de difícil repetibilidade.

Uma das metodologias mais utilizadas na seleção de genitores em programas de melhoramento genético é a análise dialélica, a qual informa a respeito do potencial dos genitores quando em combinações híbridas, da ação gênica que controla os caracteres e da existência de heterose, proporcionando grandes avanços para a seleção (RAMALHO et al., 1993). Para a análise dos cruzamentos dialélicos, existem vários métodos que possibilitam estimar a capacidade geral de combinação (CGC); porém, um dos mais empregados é o de GRIFFING (1956), que gera informações a respeito da concentração de genes predominantemente aditivos em seus efeitos (CGC) e da capacidade específica de combinação (CEC), que gera informações dos genes de efeito basicamente não-aditivo (dominância e epistasia). A análise dialélica, embora amplamente utilizada, tem como desvantagem o grande trabalho envolvido na obtenção dos híbridos e, sobretudo, nas avaliações.

O objetivo deste trabalho foi estimar a capacidade geral e específica de combinação dos caracteres peso do fruto, peso de polpa, espessura da casca, grau Brix e rendimento de polpa de 12 genitores de maracujazeiro doce.

\section{MATERIAL E MÉTODOS}

Todos os experimentos foram conduzidos na estação experimental da EPAGRI situada a 28 ${ }^{\circ} 31^{\prime}$ latitude sul e $49^{\circ} 19^{\prime}$ longitude oeste e a uma altitude de 48m, no município de Urussanga - SC. Os genitores de Passiflora alata Curtis empregados na análise dialélica foram obtidos de uma coleção de 1.250 genótipos meio irmãos pertencentes à EPAGRI, oriundos da hibridação de 25 genitores femininos com um genitor masculino. Desta população de meio-irmãos, foram selecionados 12 genótipos fenotipicamente contrastantes para os caracteres de frutos: rendimento de polpa, peso médio e espessura da casca (Tabela 1). Os 12 genótipos selecionados foram cruzados na forma de um dialelo parcial, sendo seis utilizados como genitores masculinos (pais, denominados de P1 a P6) e seis como genitores femininos (mães, denominados de M1 a M6). Foram realizados 36 cruzamentos dirigidos (polinização manual) para garantir a fidelidade dos cruzamentos, as

\begin{tabular}{|c|c|c|c|}
\hline Genitores & RP (\%) & $\mathrm{PF}(\mathrm{g})$ & $\mathrm{EC}(\mathrm{mm})$ \\
\hline M 1 & 35,2 & 250 & 11,0 \\
\hline M 2 & 39,4 & 179 & 10,0 \\
\hline M 3 & 35,5 & 255 & 8,5 \\
\hline M 4 & 35,7 & 263 & 9,5 \\
\hline M 5 & 37,6 & 203 & 9,0 \\
\hline M 6 & 33,3 & 176 & 8,5 \\
\hline P 1 & 24,9 & 334 & 13,0 \\
\hline P 2 & 23,4 & 192 & 12,0 \\
\hline P 3 & 20,6 & 199 & 9,0 \\
\hline P 4 & 29,3 & 210 & 11,5 \\
\hline P 5 & 26,6 & 270 & 10,5 \\
\hline P 6 & 21,7 & 220 & 12,5 \\
\hline
\end{tabular}

Ciência Rural, v.37, n.4, jul-ago, 2007. 
flores foram cobertas antes da antese e emasculadas antes da polinização.

Em cada um dos cruzamentos, foi obtido um número mínimo de sementes que viabilizasse a obtenção de ao menos 32 plântulas (segregantes) por cruzamento. As sementes foram postas para germinar em casa de vegetação e, posteriormente, as mudas foram transplantadas para o campo. Em cada cova foram alocadas duas mudas e, após o seu total estabelecimento, foi mantida uma planta por cova, restando então 576 plantas $\mathrm{F}_{1} \mathrm{~s}$ segregantes e 192 plantas genitoras obtidas por estaquia.

$\mathrm{O}$ experimento foi conduzido na forma de blocos completos casualizados com quatro repetições, incluindo $\mathrm{F}_{1} \mathrm{~s}$ e genitores. Cada bloco foi composto por 48 tratamentos ( 36 cruzamentos e os 12 genitores). Nas parcelas experimentais, as plantas foram mantidas no espaçamento de $1 \mathrm{~m}$ entre plantas e 2,5m entre linhas e conduzidas no sistema de espaldeira. Foram avaliados 10 frutos por planta, quanto aos caracteres: peso do fruto $(\mathrm{PF})$, peso da polpa (PP), espessura da casca (EC), grau Brix (GB) e rendimento de polpa (RP). As avaliações feitas foram: peso de cada fruto, espessura da casca (utilizando-se um paquímetro), peso da polpa e grau Brix, com a utilização de um refratômetro. O rendimento de polpa foi estimado dividindo-se o peso da polpa pelo peso total do fruto.

Os dados obtidos foram submetidos à análise de variância univariada (considerando-se fixos os efeitos dos tratamentos) e ao teste $\mathrm{F}$ a $5 \%$ de probabilidade de erro. As médias (das quatro repetições) dos genitores e da $\mathrm{F}_{1} \mathrm{~s}$ foram analisadas de acordo com o modelo de dialelo parcial proposto por GERALDI e MIRANDA FILHO (1988), que é uma adaptação do modelo proposto por GRIFFING (1956). O modelo apresenta uma decomposição da soma de quadrados de tratamentos em somas de quadrados associados à capacidade combinatória dos dialelos parciais que incluem os genitores, sendo: $Y_{i j}=\mu+1 / 2\left(d_{1}+d_{2}\right)+g_{i}+g_{j}^{\prime}+S_{i j}+\varepsilon_{i j}$, em que $\mathrm{Y}_{\mathrm{ij}}$ é a média do cruzamento envolvendo o i-ésimo genitor do grupo 1 e o j-ésimo genitor do grupo 2; $\mu$ é a média geral do dialelo; $\mathrm{d}_{1}$ e $\mathrm{d}_{2}$ são os contrastes envolvendo as médias dos grupos 1 e 2 e a média geral do dialelo; $g_{\mathrm{i}}$ é o efeito da capacidade geral de combinação do i-ésimo genitor do grupo $1 ; \mathrm{g}_{\mathrm{j}}$ é o efeito da capacidade geral de combinação do j-ésimo genitor do grupo 2; $\mathrm{S}_{\mathrm{ij}}$ o efeito da capacidade específica de combinação e $\mathrm{e}_{\mathrm{ij}}$ é o erro experimental médio.

$\mathrm{O}$ ranking dos genitores em relação à capacidade geral de combinação (CGC) e às médias $(\mu)$ para os caracteres do fruto foi elaborado atribuindo-se valores de 1 a 6, em ordem decrescente de importância, recebendo a atribuição 1 (um) o genitor que apresentou a menor capacidade geral de combinação e valor 6 (seis) o genitor com maior valor para CGC. O mesmo critério foi adotado para a média. Posteriormente, foi estimada a média da ordem de classificação de cada genitor para CGC e para a média dos caracteres aferidos. Por fim, a média dessas duas médias foi utilizada para o ranking geral dos genitores para fins de melhoramento.

\section{RESULTADOS E DISCUSSÃO}

$\mathrm{O}$ teste $\mathrm{F}$ da análise de variância revelou a inexistência de diferenças estatisticamente significativas entre os tratamentos para os caracteres peso do fruto, peso da polpa e grau Brix (Tabela 2). Duas razões devem estar envolvidas com os resultados: a relativa similaridade genética (meio-irmãos) entre os genitores utilizados e a variabilidade genética de magnitude similar dentro das famílias geradas. Estes fatores provavelmente ocasionaram grande similaridade entre as médias das populações segregantes e dos genitores. Ou seja, como os genitores eram muito similares, os mesmos não propiciaram uma variação de magnitude tal que permitisse a detecção de diferenças significativas para tais caracteres. FIDELIS (2003) encontrou resultados semelhantes para a produção de grãos de milho, cuja CGC do grupo melhorado não foi significativa, indicando que as cultivares melhoradas tinham variância genética aditiva semelhante entre si. Os coeficientes de variação para os caracteres peso do fruto, peso da polpa, e grau Brix foram relativamente baixos, variando de 3,3 a 9,6\%. Esses valores demonstram pouca variação genética e a elevada precisão experimental obtida e, ao mesmo tempo, afastaram a hipótese da inexistência de diferenças significativas entre os tratamentos ter por base uma elevada variação ambiental (Tabela 2).

Entretanto, para os caracteres espessura da casca e rendimento de polpa, o teste F detectou a existência de diferenças significativas entre os tratamentos. Para estes caracteres, apesar de os genitores serem geneticamente similares, os mesmos mantiveram uma variabilidade de tal magnitude que permitiu a detecção de diferenças estatisticamente significativas entre os tratamentos. Possivelmente, tal fato seja um indicativo da existência de uma grande variabilidade para estes caracteres (EC e RP), mesmo entre os genitores (meio-irmãos) de maracujazeiro doce avaliados. Estas duas características são de extrema importância na comercialização de frutos dessa espécie, pois frutos com maior quantidade de polpa em relação ao peso total é um dos objetivos básicos dos programas de 
Tabela 2 - Resumo da análise de variância (nos híbridos $\mathrm{F}_{1}$ e nos 12 genitores) e os valores e significância dos quadrados médios da análise conjunta de variância para capacidade geral de combinação (CGC) e capacidade específica de combinação (CEC) para os caracteres peso do fruto (PF), peso da polpa (PP), espessura da casca (EC), grau Brix (GB) e rendimento de polpa (RP). CCA/UFSC, Florianópolis, 2006.

\begin{tabular}{|c|c|c|c|c|c|c|}
\hline Fonte de variação & GL & $\mathrm{PF}(\mathrm{g})$ & PP (g) & $\mathrm{EC}(\mathrm{mm})$ & GB & $\mathrm{RP}(\%)$ \\
\hline QM Tratamentos & 47 & 192,49 & 48,15 & $0,87 *$ & 0,29 & $6,62 *$ \\
\hline QM Resíduo & 141 & 265,07 & 39,96 & 0,46 & 0,35 & 4,49 \\
\hline CV (\%) & & 7,60 & 9,62 & 7,25 & 3,29 & 6,89 \\
\hline Grupos & 1 & 0,0008 & $679,80 *$ & $2,90 *$ & 0,45 & $157,54 *$ \\
\hline CGC (Mães) & 5 & 208,73 & 38,03 & $1,62 *$ & 0,50 & 1,83 \\
\hline CGC (Pais) & 5 & 540,80 & $110,10^{*}$ & 0,89 & 0,30 & 3,04 \\
\hline CEC & 36 & 146,87 & 23,31 & 0,70 & 0,26 & 3,60 \\
\hline Resíduo & 141 & 265,07 & 39,96 & 0,46 & 0,35 & 4,49 \\
\hline $\mathrm{CV}(\%)$ & & 7,6 & 9,6 & 7,2 & 3,3 & 6,9 \\
\hline Média & & 214,07 & 65,66 & 9,38 & 18,04 & 30,76 \\
\hline
\end{tabular}

* Significativo a $5 \%$ de probabilidade de erro pelo teste F.

melhoramento genético. Novamente, para esses caracteres, os coeficientes de variação foram de pequena magnitude, 7,2 (EC) e 6,9\% (RP), indicando elevada confiabilidade nos resultados obtidos (Tabela 2).

A análise de variância de acordo com o modelo dialélico revelou efeitos significativos entre grupos (pais x mães) para os caracteres PP, EC e RP, significância para capacidade geral de combinação (CGC) somente para o caráter EC entre os genitores femininos e para o caráter PP entre os genitores masculinos e nenhum efeito significativo foi detectado para capacidade específica de combinação (Tabela 2). A existência de poucos efeitos significativos é um reflexo direto da grande similaridade genética presente entre os genitores empregados na análise (meioirmãos). Os coeficientes de variação foram de baixa magnitude, variando de 3,3 a 9,6\%, conferindo elevada precisão experimental às avaliações realizadas e a reduzida variação genética.
Para o caráter peso de fruto (PF), não foram detectadas diferenças significativas para nenhum dos efeitos estudados (Tabela 2), o que é um indicativo de que os genitores estudados evidenciam variâncias genéticas aditivas e não-aditivas (dominância e epistasia) muito semelhantes e pouca variabilidade genética, além de evidenciarem médias semelhantes para o caráter PF. Como conseqüência, foi detectada uma pequena diferença entre a média geral dos cruzamentos e a média dos pais e das mães, como revelou o contraste que foi praticamente nulo (Tabela 3). Entretanto, é relevante ressaltar que o genitor masculino $\mathrm{P} 5$ foi o que evidenciou a maior CGC $(+6,20$, Tabela 3). Os maiores valores para CEC foram detectados para os cruzamentos $1 \times 2(+9,06), 3 \times 4(+$ $7,96), 4$ × $3(+10,94)$ e $6 \times 4(+11,23)$, que apresentaram peso do fruto médio de 217,6, 219,8, 223,2 e 226,6 g, respectivamente (Tabela 4). O cruzamento que apresentou o maior potencial para utilização foi o $2 \times 5$,

Tabela 3 - Estimativa dos efeitos da CGC dos 12 genitores para os caracteres peso do fruto (PF), peso da polpa (PP), espessura da casca (EC), grau Brix (GB) e rendimento de polpa (RP). CCA/UFSC, Florianópolis, 2006.

\begin{tabular}{|c|c|c|c|c|c|c|c|c|c|c|}
\hline \multirow[t]{2}{*}{ Genitor } & \multicolumn{2}{|c|}{$\mathrm{PF}(\mathrm{g})$} & \multicolumn{2}{|c|}{$\mathrm{PP}(\mathrm{g})$} & \multicolumn{2}{|c|}{$\mathrm{EC}(\mathrm{mm})$} & \multicolumn{2}{|c|}{ GB } & \multicolumn{2}{|c|}{ RP (\%) } \\
\hline & Mãe & Pai & Mãe & Pai & Mãe & Pai & Mãe & Pai & Mãe & Pai \\
\hline 1 & $-2,69$ & $+1,61$ & $-1,45$ & $+0,83$ & $+0,32$ & $+0,17$ & $-0,11$ & $-0,11$ & $-0,29$ & $+0,17$ \\
\hline 2 & $-0,38$ & $-2,89$ & $+0,28$ & $-1,20$ & $+0,06$ & $+0,009$ & $+0,09$ & $+0,10$ & $+0,25$ & $-0,16$ \\
\hline 3 & $-0,47$ & $-3,82$ & $+0,24$ & $-1,49$ & $-0,17$ & $-0,21$ & $-0,11$ & $+0,05$ & $+0,12$ & $-0,12$ \\
\hline 4 & $+2,93$ & $-1,75$ & $+1,26$ & $-0,65$ & $+0,07$ & $+0,005$ & $-0,03$ & $-0,03$ & $+0,17$ & $-0,03$ \\
\hline 5 & $-1,89$ & $+6,20$ & $-0,81$ & $+2,96$ & $-0,23$ & $-0,12$ & $+0,16$ & $-0,08$ & $-0,08$ & $+0,45$ \\
\hline 6 & $+2,50$ & $+0,65$ & $+0,47$ & $-0,43$ & $-0,06$ & $+0,15$ & $+0,002$ & $+0,06$ & $-0,17$ & $-0,31$ \\
\hline Contrastes ${ }^{*}$ & 0,004 & $-0,004$ & $+3,76$ & $-3,76$ & $-0,24$ & $+0,24$ & 0,09 & $-0,09$ & 1,81 & $-1,81$ \\
\hline
\end{tabular}

${ }^{*}$ Contraste entre a média dos pais e das mães, em relação à média geral do dialelo. 
Tabela 4 - Efeitos da capacidade específica de combinação (CEC) em 36 cruzamentos de maracujazeiro doce para os caracteres peso do fruto (PF), peso da polpa (PP), espessura da casca (EC), grau Brix (GB) e rendimento de polpa (RP). CCA/UFSC, Florianópolis, 2006.

\begin{tabular}{|c|c|c|c|c|c|c|c|c|c|c|}
\hline \multirow{2}{*}{ Cruzamento } & \multicolumn{2}{|c|}{$\mathrm{PF}(\mathrm{g})$} & \multicolumn{2}{|c|}{$\mathrm{PP}(\mathrm{g})$} & \multicolumn{2}{|c|}{$\mathrm{EC}(\mathrm{mm})$} & \multicolumn{2}{|c|}{ GB } & \multicolumn{2}{|c|}{$\mathrm{RP}$} \\
\hline & CEC & $\mu$ & CEC & $\mu$ & CEC & $\mu$ & CEC & $\mu$ & CEC & $\mu$ \\
\hline $1 \times 1$ & $+0,39$ & 213,4 & $+1,01$ & 66,0 & $-0,59$ & 9,3 & $+0,20$ & 18,0 & $+0,36$ & 31,0 \\
\hline $1 \times 2$ & $+9,06$ & 217,6 & $+4,08$ & 67,1 & $-0,30$ & 9,4 & $-0,18$ & 17,8 & $+0,60$ & 30,9 \\
\hline $1 \times 3$ & $-3,85$ & 203,7 & $-1,15$ & 61,6 & $-0,02$ & 9,5 & $-0,23$ & 17,8 & $+0,11$ & 30,5 \\
\hline $1 \times 4$ & $+5,60$ & 215,3 & $+0,90$ & 64,5 & $-0,28$ & 9,4 & $+0,04$ & 17,9 & $-0,24$ & 30,2 \\
\hline $1 \times 5$ & $-0,20$ & 217,4 & $-2,44$ & 64,7 & $-0,01$ & 9,6 & $+0,11$ & 18,0 & $-1,11$ & 29,8 \\
\hline $1 \times 6$ & $+2,50$ & 214,5 & $+1,68$ & 65,5 & $+0,22$ & 10,1 & $+0,02$ & 18,0 & 0,34 & 30,5 \\
\hline $2 \times 1$ & $-9,47$ & 205,8 & $-3,44$ & 63,3 & $-0,48$ & 9,1 & $-0,30$ & 17,7 & $-0,24$ & 30,9 \\
\hline $2 \times 2$ & $+2,44$ & 213,2 & $+1,96$ & 66,7 & $-0,003$ & 9,5 & $+0,72$ & 18,3 & $+0,63$ & 31,5 \\
\hline $2 \times 3$ & $+0,59$ & 210,5 & $+1,53$ & 66,0 & $+0,009$ & 9,3 & $-0,31$ & 17,9 & $+0,88$ & 31,8 \\
\hline $2 \times 4$ & $-8,17$ & 203,7 & $-1,00$ & 64,3 & $-0,40$ & 9,1 & $-0,001$ & 18,1 & $+0,62$ & 31,6 \\
\hline $2 \times 5$ & $+3,39$ & 225,2 & $+1,75$ & 72,2 & $+0,77$ & 10,2 & $+0,15$ & 18,3 & $+0,41$ & 32,2 \\
\hline $2 \times 6$ & $-0,83$ & 213,5 & $+0,42$ & 65,9 & $-0,47$ & 9,1 & $+0,05$ & 18,3 & $+0,32$ & 31,0 \\
\hline $3 \times 1$ & $+5,24$ & 220,5 & $-0,82$ & 65,9 & $+0,57$ & 10,0 & $+0,17$ & 18,0 & $-1,03$ & 30,0 \\
\hline $3 \times 2$ & $-2,71$ & 208,0 & $-1,66$ & 63,0 & $-0,27$ & 9,0 & $-0,08$ & 18,0 & $-0,30$ & 30,4 \\
\hline $3 \times 3$ & $+1,83$ & 211,6 & $-3,14$ & 61,3 & $-0,10$ & 8,9 & $-0,17$ & 17,8 & $-1,63$ & 29,1 \\
\hline $3 \times 4$ & $+7,96$ & 219,8 & $+4,05$ & 69,3 & $-0,10$ & 9,1 & $-0,09$ & 17,9 & $+0,87$ & 31,7 \\
\hline $3 \times 5$ & $-4,46$ & 215,3 & $-1,83$ & 67,0 & $-0,07$ & 9,0 & $+0,16$ & 18,0 & $-0,32$ & 31,0 \\
\hline $3 \times 6$ & $-14,73$ & 199,5 & $-0,38$ & 65,1 & $+0,43$ & 9,8 & $-0,07$ & 17,9 & $+1,99$ & 32,6 \\
\hline $4 \times 1$ & $-2,38$ & 216,2 & $+0,43$ & 68,2 & $+0,38$ & 10,0 & $+0,24$ & 18,1 & $+0,52$ & 31,6 \\
\hline $4 \times 2$ & $-7,42$ & 206,7 & $-2,53$ & 63,2 & $+0,24$ & 9,7 & $-0,10$ & 18,0 & $-0,16$ & 30,6 \\
\hline $4 \times 3$ & $+10,94$ & 223,2 & $+5,28$ & 70,7 & $+0,70$ & 9,9 & $+0,05$ & 18,2 & $+0,95$ & 31,9 \\
\hline $4 \times 4$ & $-3,75$ & 211,5 & $-1,66$ & 64,6 & $-0,54$ & 8,9 & $+0,08$ & 18,1 & $-0,21$ & 30,7 \\
\hline $4 \times 5$ & $-4,67$ & 218,5 & $-1,78$ & 68,1 & $-0,22$ & 9,1 & $+0,38$ & 18,3 & $-0,17$ & 31,2 \\
\hline $4 \times 6$ & $+4,32$ & 222,0 & $+1,88$ & 68,4 & $-0,75$ & 8,9 & $+0,03$ & 18,1 & $+0,37$ & 31,0 \\
\hline $5 \times 1$ & $+3,16$ & 217,0 & $+2,14$ & 67,8 & $-0,05$ & 9,3 & $-0,12$ & 18,0 & $+0,57$ & 31,4 \\
\hline $5 \times 2$ & $-3,73$ & 205,6 & $+3,45$ & 67,1 & $+0,44$ & 9,6 & $-0,04$ & 18,3 & $+2,20$ & 32,7 \\
\hline $5 \times 3$ & $-3,85$ & 204,5 & $+1,09$ & 64,4 & $+0,39$ & 9,3 & $+0,64$ & 18,0 & $+1,20$ & 31,8 \\
\hline $5 \times 4$ & $-2,14$ & 208,3 & $-2,26$ & 61,9 & $-0,06$ & 9,1 & +0.06 & 18,2 & $-0,64$ & 30,0 \\
\hline $5 \times 5$ & $-3,91$ & 214,5 & $-0,60$ & 67,2 & $-0,38$ & 8,7 & $-0,11$ & 18,0 & $+0,12$ & 31,3 \\
\hline $5 \times 6$ & $+3,82$ & 216,7 & $-0,16$ & 64,2 & $-0,16$ & 9,1 & $-0,30$ & 18,0 & $-0,61$ & 29,8 \\
\hline $6 \times 1$ & $-1,78$ & 216,4 & $-0,43$ & 66,5 & $-0,20$ & 9,3 & $-0,06$ & 17,9 & $+0,24$ & 31,0 \\
\hline $6 \times 2$ & $+4,17$ & 217,9 & $-0,75$ & 64,2 & $+0,34$ & 9,7 & $-0,22$ & 17,9 & $-0,88$ & 29,5 \\
\hline $6 \times 3$ & $-2,70$ & 210,0 & $+0,29$ & 64,9 & $+0,007$ & 9,1 & $+0,17$ & 18,3 & $+0,49$ & 31,0 \\
\hline $6 \times 4$ & $+11,23$ & 226,1 & $+3,22$ & 68,7 & $+0,37$ & 9,7 & $-0,14$ & 17,9 & $-0,08$ & 30,5 \\
\hline $6 \times 5$ & $-1,78$ & 221,0 & $-1,83$ & 67,3 & $-0,56$ & 9,1 & $+0,18$ & 18,2 & $-0,56$ & 30,5 \\
\hline $6 \times 6$ & $-0,19$ & 217,0 & $+1,25$ & 67,0 & $-0,36$ & 9,1 & $-0,11$ & 18,0 & $+0,56$ & 30,8 \\
\hline Média & & 213,9 & & 65,9 & & 9,4 & & 18,0 & & 30,9 \\
\hline
\end{tabular}

que evidenciou elevada CEC, envolveu o genitor com maior CGC para o caráter PF (P5) e revelou média elevada de 225,2g (Tabela 3 ).

Em relação ao caráter peso de polpa (PP), a análise dialélica evidenciou diferenças significativas entre os grupos (genitores) e para CGC entre pais (grupo I), indicando que os pais contribuem de maneira diferenciada para o caráter peso da polpa e que existem diferenças entre as contribuições para esse caráter entre os genótipos empregados como pais e mães (Tabela 2). Nos valores encontrados para os contrastes em relação às médias do grupo $\mathrm{I}\left(\mathrm{d}_{1}=+3,76\right)$ e grupo II $\left(\mathrm{d}_{2}=\right.$ $-3,76)$ e a média geral, verificou-se que a média das mães foi superior à média dos pais (Tabela 3 ). Esses resultados indicam que os genitores utilizados como mães no dialelo evidenciam uma média mais elevada que os utilizados como pais. Em relação à CEC (Tabela 2), não foram encontrados valores que diferissem estatisticamente entre si para o caráter analisado. Esse resultado demonstra a existência de variabilidade para efeitos gênicos aditivos e não para os efeitos nãoaditivos. Dentre os genitores masculinos, o que 
evidenciou a maior CGC foi novamente o P5 $(+2,96)$, que já havia se destacado como maior CGC para o $\mathrm{PF}, \mathrm{o}$ que é um indicativo de que tal genitor apresenta tanto a capacidade de transmitir genes aditivos que elevam o $\mathrm{PP}$ como o $\mathrm{PF}$ (Tabela 2). Em relação à $\mathrm{CEC}$, o teste $\mathrm{F}$ mostrou que os valores não diferiram estatisticamente entre si, sendo que o cruzamento $4 \times 3(+5,28)$ apresentou a maior estimativa para a CEC, cuja média foi de 70,7 g (Tabela 4). Contudo, conforme CRUZ \& REGAZZI (1997), para que um cruzamento seja recomendado, o mesmo precisa evidenciar elevada média e CEC e pelo menos um dos genitores apresentar elevada CGC. Dessta forma, o cruzamento com maior potencial para utilização foi o $2 \times 5$, que evidenciou elevada CEC, envolveu o genitor com maior CGC para o caráter PP (P5) e evidenciou média elevada 72,2g (Tabela 3).

Para o caráter espessura da casca, verificouse que os genitores apresentaram diferenças estatisticamente significativas para a CGC entre mães e entre grupos de genitores e não-significativas para a $\mathrm{CEC}$, indicando-se que dentro da variação genotípica há predomínio dos efeitos aditivos sobre os nãoaditivos entre as mães (Tabela 2). RESENDE et al. (2003) encontraram diferenças significativas para a CGC e nãosignificativas para a CEC na firmeza dos frutos do tomateiro, no décimo dia de prateleira, o que demonstra ser o referido caráter controlado, principalmente, por genes com efeitos aditivos. Nesse caso, resultados similares foram encontrados para as duas espécies. A análise dos contrastes em relação às médias do grupo $\mathrm{I}\left(\mathrm{d}_{1}=-0,24\right)$ e do grupo II $\left(\mathrm{d}_{2}=+0,24\right)$ e à média geral, revelou que a média dos pais foi superior à média das mães em termos de espessura da casca (Tabela 3). Dentre os genitores femininos, a M1 foi a que evidenciou a maior CGC $(+0,37)$, evidenciando que tal genitor tem uma boa capacidade de transmitir genes aditivos que conferem um incremento na EC (Tabela 3). As duas combinações com maior CEC foram 2 x $5(+0,77)$ e 4 x 3 $(+0,70)$, que apresentaram os maiores valores para a CEC e valores de médias de 10,2 e 9,9mm, respectivamente (Tabela 4). Dentre os cruzamentos estudados, o que apresenta maior potencial para utilização é o 1 x 6 , que evidenciou CEC positiva $(+0,22)$ e envolveu o genitor com maior CGC para o caráter EC (M1) e evidenciou média elevada de 10,1 mm (Tabela 3).

Não foram detectadas diferenças significativas para nenhum dos efeitos estudados para o caráter grau Brix (Tabela 2), o que é um indicativo de que os genitores estudados evidenciam variâncias genéticas aditivas e não-aditivas (dominância e epistasia) semelhantes, pouca variabilidade genética, além de evidenciarem também médias semelhantes para o caráter GB (Tabela 3). Dentre todos os genitores estudados, o que evidenciou a maior CGC foi a M5 $(+0,16)$, estatisticamente não diferente dos demais genitores (Tabela 3 ). Para a CEC, o cruzamento $2 \times 2$ se destacou por apresentar a maior estimativa da CEC ( + 0,72 ; não significativa) e média de 18,3 (Tabela 4). Dentro dos cruzamentos envolvendo a M5, o que evidenciou a maior CEC foi 5 x $2(+0,44)$; e média de 9,6 , acima da média geral (Tabela 4).

Em relação ao rendimento de polpa, a análise dialélica revelou a existência de diferenças estatisticamente significativas entre os grupos de genitores (pais x mães) e a inexistência de diferenças significativas para CGC e para CEC (Tabela 2). A existência de diferenças entre os grupos de genitores refletiu-se nos contrastes em relação às médias do grupo I $\left(\mathrm{d}_{1}=1,81\right)$ e do grupo II $\left(\mathrm{d}_{2}=-1,81\right)$ e à média geral. Também foi verificado que a média das mães foi superior à média dos pais (Tabela 3 ). P5 foi o genótipo que evidenciou a maior CGC, destacando-se também para PF e PP (Tabela 3), o que sugere sua utilização em cruzamentos que objetivem a seleção de segregantes para essas características. As melhores performances em termos de CEC foram dos cruzamentos 3 x $6(+1,99)$ e 5 x $2(+2,20)$, que apresentaram os maiores valores para a CEC e médias de 32,6 e 32,7, respectivamente. Dentro dos cruzamentos envolvendo a P5, o que evidenciou a maior CEC foi 2 × $5(+0,41)$, apresentando ainda média elevada $(32,2 \%)$. Dessa forma, tal cruzamento merece destaque, sendo ainda importante caso se objetive elevar de forma conjunta PF, PP e RP (Tabela 4).

Em relação ao ranking proposto neste trabalho, no Grupo I (mães), as melhores performances foram obtidas pelas mães 2 e 6, enquanto que no Grupo II (pais), o pai 5 alcançou a melhor performance (Tabela 5). Dessa forma, esses genitores são recomendados para a realização de futuros cruzamentos, pois já há um indicativo de que suas progênies são iguais ou superiores às de outros parentais. Destaque especial deve ser dado à combinação M2 x P5, que se revelou a melhor combinação para incrementar de forma conjunta as médias dos caracteres PF, PP e RP, que são todos caracteres intimamente relacionados com a produtividade de planta. Tal cenário pode ter por base a existência de uma forte correlação entre tais caracteres. Também foi possível identificar outros cruzamentos que resultaram em híbridos superiores, com elevadas CEC e médias para os caracteres aferidos, destacando-se as combinações 4 x 3 e 6 x 4 .

A possibilidade de predição dos ganhos obtidos por uma seleção constitui-se em uma das principais contribuições da genética quantitativa. 
Tabela 5 - Ranking dos pais em relação à Capacidade Geral de Combinação (CGC) e às médias ( $\mu$ ) para as características peso do fruto (PF), peso da polpa (PP), espessura da casca (EC), grau Brix (GB) e rendimento de polpa (RP). CCA/UFSC, Florianópolis, 2006.

\begin{tabular}{|c|c|c|c|c|c|c|c|c|c|c|c|c|c|c|}
\hline \multirow{2}{*}{ Genitores } & \multicolumn{2}{|c|}{$\mathrm{PF}(\mathrm{g})$} & \multicolumn{2}{|c|}{ PP (g) } & \multicolumn{2}{|c|}{$\mathrm{EC}(\mathrm{mm})$} & \multicolumn{2}{|c|}{ GB } & \multicolumn{2}{|c|}{ RP (\%) } & \multicolumn{2}{|c|}{ Média } & \multirow{2}{*}{ Média } & \multirow{2}{*}{$\begin{array}{l}\text { Classificação } \\
\text { final }\end{array}$} \\
\hline & CGC & $\mu$ & CGC & $\mu$ & CGC & $\mu$ & CGC & $\mu$ & $\mathrm{CGC}$ & $\mu$ & $\mathrm{CGC}$ & $\mu$ & & \\
\hline M1 & 1 & 3 & 1 & 1 & 1 & 1 & 1 & 2 & 1 & 3 & 1,0 & 2,0 & 1,5 & $5^{0}$ \\
\hline M2 & 4 & 5 & 4 & 3 & 3 & 3 & 4 & 5 & 6 & 4 & 4,2 & 4,0 & 4,1 & $1^{\underline{o}}$ \\
\hline M3 & 3 & 6 & 3 & 5 & 5 & 4 & 1 & 1 & 4 & 5 & 3,2 & 4,2 & 3,7 & $2^{\underline{o}}$ \\
\hline M4 & 6 & 1 & 6 & 1 & 2 & 2 & 2 & 2 & 5 & 1 & 4,2 & 1,4 & 2,8 & $4^{\circ}$ \\
\hline M5 & 2 & 4 & 2 & 2 & 6 & 5 & 5 & 3 & 3 & 2 & 3,6 & 3,2 & 3,4 & $3^{-}$ \\
\hline M6 & 5 & 2 & 5 & 4 & 4 & 6 & 3 & 4 & 2 & 6 & 3,8 & 4,4 & 4,1 & $1^{\underline{o}}$ \\
\hline P1 & 5 & 5 & 5 & 5 & 1 & 2 & 1 & 2 & 5 & 4 & 3,4 & 3,6 & 3,5 & $2^{\underline{o}}$ \\
\hline P2 & 2 & 3 & 2 & 4 & 3 & 4 & 6 & 4 & 2 & 5 & 3,0 & 4,0 & 3,5 & $2^{\underline{o}}$ \\
\hline P3 & 1 & 2 & 1 & 1 & 6 & 6 & 4 & 5 & 3 & 2 & 3,0 & 3,2 & 3,1 & $3^{\circ}$ \\
\hline P4 & 3 & 1 & 3 & 3 & 4 & 3 & 3 & 3 & 4 & 3 & 3,4 & 2,6 & 3,0 & $4^{\circ}$ \\
\hline P5 & 6 & 6 & 6 & 6 & 5 & 5 & 2 & 1 & 6 & 6 & 5,0 & 4,8 & 4,9 & $1^{\mathrm{o}}$ \\
\hline P6 & 4 & 4 & 4 & 2 & 2 & 1 & 5 & 6 & 1 & 1 & 3,2 & 2,8 & 3,0 & $4^{-}$ \\
\hline
\end{tabular}

Assim, por meio das informações obtidas neste trabalho, é possível orientar de maneira mais efetiva o programa de melhoramento, predizer o sucesso do esquema seletivo adotado e decidir, com base científica, por técnicas alternativas que possam ser mais eficazes para os caracteres do maracujazeiro doce aqui avaliados.

\section{CONCLUSÃO}

Dois genótipos utilizados como genitores femininos (M2 e M6) e um como genitor masculino (P5) foram classificados como os melhores no ranking dos caracteres analisados, e podem ser indicados como possíveis genitores em futuros cruzamentos dirigidos.

\section{AGRADECIMENTOS}

Os autores agradecem à UNISUL pelo apoio a M.S.J; à EPAGRI, pelo material vegetal e campo experimental e ao CNPq, pela bolsa a R.O.N.

\section{REFERÊNCIAS}

ALLARD, R.W. Principies of plant breeding. 2.ed. New York: John Wiley \& Sons, 1999. 254p.

CRUZ, C.D.; REGAZZI, A.J. Modelos biométricos aplicados ao melhoramento genético. Viçosa: UFV, 1997. 390p.

COSTA, A.M.; TUPINAMBÁ, D.D. O maracujá e suas propriedades medicinais - estado da arte. In: FALEIRO, F.G. et al. Maracujá germoplasma e melhoramento genético. Planaltina: Embrapa Cerrados, 2005. Cap 20, p.475-506.

FALEIRO, F.G. et al. Germoplasma e melhoramento genético do maracujazeiro - desafios da pesquisa. In: FALEIRO, F.G. et a1. Maracujá germoplasma e melhoramento genético. Planaltina: Embrapa Cerrados, 2005. Cap.08, p.187-209.

FERRARI, R.A. et al. Caracterização de subprodutos da industrialização do maracujá - aproveitamento de sementes. Revista Brasileira de Fruticultura, Jaboticabal, v.26, n.1, p.101-102, 2004.

FIDELIS, R.R. Capacidade de combinação de cultivares locais e melhorados de milho sob estresse de baixo nitrogênio. 2003. 90f. Tese (Doutorado em Produção Vegetal) - Programa de Pós-graduação em Fitotecnia, Universidade Federal de Viçosa.

GERALDI, I.O.; MIRANDA FILHO, J.B. Adapted models for the analysis of combining ability of varieties in partial diallel crosses. Revista Brasileira de Genética, Ribeirão Preto, v.11, n.2, p.419-430, 1988.

GRIFFING, B. Concept of general and specific combining ability in relation to diallell crossing systems. Australian Journal of Biology Sciences, East Melbourn, v.9, n.3, p.463-493, 1956.

JUNQUEIRA, N.T.V. et al. Melhoramento genético do maracujádoce. In: MANICA, I. et al. (Org). Maracujá-doce: tecnologia de produção, pós-colheita, mercado. Porto Alegre: Cinco Continentes, 2005. V.1, p.39-46.

KUSKOSKI, E.M. et al. Frutos tropicais silvestres e polpas congeladas: atividade antioxidante, polifenóis e antocianinas. Ciência Rural, Santa Maria, v.36, n.4, p.1283-1287, 2006.

RAMALHO, M.A. et al. Genética quantitativa em plantas autógamas. Goiânia: UFG, 1993. 271p.

RESENDE, L.V. et al. Análise dialélica de firmeza de frutos em cultivares e linhagens de tomateiro (Lycopersicon esculentum Mill). Ciência e Agrotecnologia, Lavras, v.23, n.1, p.8-14, 2003.

SOUZA, J.S.I.; MELETTI, L.M.M. Maracujá: espécies, variedades e cultivos. Piracicaba: FEALQ, 1997. 179p. 